\title{
Employee' Assessment of Conflict Factors in the Organization: Healthcare Companies Case Study
}

\author{
Inna Kulkova ${ }^{1}{ }^{*}$ Irina Niyazova ${ }^{2}$ \\ ${ }^{I}$ Ural State University of Economics, Institute of Economics of the Ural Branch of the Russian Academy of Science, \\ Russia \\ ${ }^{2}$ Tyumen Regional narcological Dispensary, Russia \\ *Email: i.a.koulkova@mail.ru
}

\begin{abstract}
The article is dedicated to the study of the causes of the conflict in healthcare companies. The research contains the analysis of the medical staff's opinion poll results devoted to the factors of the conflicts and fulfilled by the author. The total number of respondents was 264 men and women in the Ural Federal District. The opinion poll allowed the identification of negative factors during the medical staff working process, which can cause conflict, be the basis for professional burnout, and decrease performance motivation. The following factors were highlighted among them: constant alterations in the routine work of medical staff, high level of workload, and low-level wages, especially for medical nurses. It was defined that the basic conflict source is an imbalance in interests of medical staff and patients and the general growing discontent of the healthcare system with the latest.
\end{abstract}

Keywords: Conflict inside a company/organization, Causes of conflict, Healthcare companies, Head's role in the conflict, Conflict with patients.

\section{INTRODUCTION}

In contemporary conditions, the efficient management of human resources in the company is impossible without the organized system of conflict management. The in-house conflict is a disagreement state between people working together, which can be caused by both actual and perceived antagonism of their needs, values, and interests [1]. The causes of the conflict inside the company can be objective and subjective. In 2002 Art Bell [2] identified six causes of conflict inside the company: the existence of opposite needs, different behavior style collision, the opposite perception of the situation, the presence of antagonistic goals, pressure on employees from different mutually exclusive sides, and the presence of roles conflict. Later, Brett Hart [3] extended the list of causes with two more ones: personal values difference and carrying-out of unpredictable policy.

Management's conflictology inside the company is quite a new science, though Karl Marx is acknowledged to be the father of it because he grounded the origin of interests conflict between various social groups by the presence of exploitation. He did not study conflicts on the level of one company, that is why the theoretical basis for this research can be called the works of C. Wright Mills [4], who confirmed that social structures are developed as a result of conflict between people with different interests and resources.

Nowadays the reasons for interest conflicts, which take place inside a company, are a topical research subject in the sphere of industrial companies [5] and agro-industrial complexes [6], power supply companies [7], and staff members of educational [8] and medical organizations [9]. Special interest is aroused by conflict settlement methods, thus, for example, L.K. Gabdulhakova summarized the existing in scientific literature approaches to conflict settlement (avoidance or withdrawal, conflict as a natural phenomenon, a reason for adjustive actions from management, and conflict stimulation and maintenance [10]. As far as interest conflicts management the authors consider the special programs of staff training, especially integral ones (for example [11]) as the most efficient method to 
manage the conflicts. At the same time, there is no consistent approach to defining the conflict essence in a company [12], and identifying conflict factors; there is a differentiation between theoretical and empirical research areas, which preconditions the necessity for further study of conflict causes and their settlement lines inside a company.

The purpose of this study is to analyze conflict factors marked by medical staff. Each medical company is characterized by conflicts existence, including conflicts of interest, which are understood as situations when an employee is involved in several financial or other interests, while the settlement of one interest contradicts professional activities to settle another [13].

\section{RESEARCH METHODS}

To identify staff opinions about conflicts factors inside their medical companies the authors conducted social polling of medical specialists and medical nurses. The total number of respondents was 264 people, who worked in three medical state organizations of the Ural Federal district. The proportion of respondent-women is higher $(78.4 \%$ of the total were women, $21.6 \%$ of the total were men). This is due to the fact that the medical care area is quite feminized in the Russian Federation. As the Minister of Health of the Russian Federation Veronika Skvortsova declared at the II Eurasian Women's Forum, which was held in St. Petersburg on September 19-21, 2018, "in general, women [doctors] prevail in our country - this is $71 \%$ of all doctors and more than $95 \%$ of medical nurses".

Polling was conducted in November-December 2019 at the working places (field study) on the basis of the questionnaire developed by the authors. The sampling error at the confidence interval for the ratio of $95 \%$ was $+/-4.1 \%$.

The survey results were put into an electronic database and were processed using a special computer program, which excludes the possibility of arithmetic errors in calculations.

\section{RESEARCH RESULTS}

The survey results evidenced that the constant alterations, which take place in companies, have the most negative impact on the medical staff work activity. It was marked by $39.8 \%$ of respondents (table 1 ). Therewith it should be noted that the survey was conducted before the COVID-19 pandemic, and even then, medical staff noted a large number of changes in their work, which took place on a permanent basis. At the present moment, the number of changes in the workplace has increased significantly due to the appeared restrictions. The poor-quality organization of staff work was marked by $30.7 \%$ of the staff respondents, as well as the unsatisfying work-flow organizing system with patients (marked by $30.7 \%$ of the respondents). These conflicts causes can be eliminated, and they are indicators of poor management in organizations. Interaction with colleagues is another reason for conflicts, which was marked by $28.4 \%$ of respondents. It should be noted that the amount of answers to this question is more than $100 \%$ because respondents could mark not more than 3 variants, which have the most impact as per their opinion.

The least number of answers has the following reasons: management actions $(10.2 \%)$, over-prescribed load $(4.5 \%)$, bureaucratization $(2.3 \%)$, working area availability $(2.1 \%)$. Only $3.4 \%$ of respondents have the

Table 1. The distribution of answers as for factors with a negative impact on the work process and work motivation of the staff

\begin{tabular}{|l|c|l|c|}
\hline Factors of negative impact on the work process & $\begin{array}{c}\text { Answered } \\
\text { positive rate, } \\
\%\end{array}$ & $\begin{array}{l}\text { Factors of negative impact on the work } \\
\text { motivation }\end{array}$ & $\begin{array}{c}\text { Answered } \\
\text { positive rate, } \%\end{array}$ \\
\hline $\begin{array}{l}\text { The existing work-flow organizing system with } \\
\text { patients }\end{array}$ & 30.7 & Low-level wages & 59.1 \\
\hline Management actions & 10.2 & Low content labor & 0.9 \\
\hline Conflict interactions with colleagues & 28.4 & High emotional stress & 50.9 \\
\hline Over prescribed load & 4.5 & Too big work volume & 13.6 \\
\hline Fast occurring changes & 39.8 & Conflicts between staff members & 45.5 \\
\hline Poor quality of staff work organization & 30.7 & Absence of professional career growth & 6.4 \\
\hline \begin{tabular}{l|l|l|} 
Bureaucratization at the Russian Federation \\
legislation level
\end{tabular} & 2.3 & Patients' complaints & 13.6 \\
\hline Working area availability & 2.3 & No such factors & 1.8 \\
\hline No impact & 3.4 & & \\
\hline
\end{tabular}


opinion that there is nothing that has a negative impact on medical staff work.

The major changes, that recently have taken place in the healthcare system, are associated with the implementation of a new financial support model for the area - a single-channel healthcare financing system. At the same time, the expenses financing sources remained, it is only the mechanism of financing institutions, their ratio and channels of admission to medical institutions that have changed. The transition to a single-channel healthcare financing system led to a redistribution of responsibility areas and institutional roles, both doctors, heads of medical institutions, and insurance companies. One of the transition stages to a single-channel financing system was the introduction of standards and procedures for medical care providing. The transition to a single-channel financing system caused the patients' attendance duration timing and, as follows, defined the work volume (load) of medical staff.

Further, it should be pointed out that $48.5 \%$ of respondents marked that a high level of workload might be the basis for professional burnout. $41.4 \%$ of respondents called changes causing professional discomfort as the possible reasons for burnout. The following reasons were marked more seldom: conflicts inside companies (16.2\%), work content (11.1\%), management actions quality $(5.1 \%)$.

Financing of medical institutions is carried out on the basis of the results of the agreed fulfilled volume of medical services as per the established tariffs. Within the financing limits all the needs and expenses, from the purchase of medicines and medical staff wages to the housing and utility services, and other economic services payments, required for the institution functioning should be covered. Malfunctions in medical institutions' activity result in fines from insurance companies, late procurement of medicines, etc. Often this has been covered by impairment of medical staff rights. As a result, the balance of applied medical staff efforts and compensation for their work is violated. It is this imbalance that is called by doctors as basic problems of the healthcare system - low-level wages, high load, and in general poor financing.

The survey also evidenced that respondents called low-level wages as one of the factors, which decreases performance motivation in $59.1 \%$ of the total observed cases. Emotional stress and conflicts between staff members $(50.9 \%$ and $45.5 \%$ of respondents respectively) were called as other important factors. At the same time, the wages level directly depends on the workload, that is the fulfillment of the specified work volumes, which are strictly controlled by the supervisory authorities of the Compulsory Health Insurance.
The respondents called less significant factors as the following: too big work volume (13.6\% of respondents), patients complaints (13.4\% of respondents), absence of professional career growth opportunities in the company (6.4\% of respondents), and low work content (monotony) $(0.9 \%$ of respondents). Only $1.8 \%$ of medical staff respondents have an opinion that there are no such factors in their company.

Excessive regulations of the medical staff activities, on the one hand, as well as the growing population demand for free medical services, on the other, lead to the social tension accumulation both in the relationship between medical staff members and patients and within the medical community.

One of the most important priorities in medical activity is working with patients. The information awareness of the Russians about the work of the compulsory healthcare insurance system remains extremely low. There is no clear understanding of the healthcare financing process, no one thinks about the cost of "free medicine". Patients in the healthcare system appear to be the consumers of services provided by medical institutions. There can be observed an imbalance in relations between doctors and patients in the Russian healthcare system. Doctors have a large number of responsibilities and few rights, while patients have such imbalance in the opposite direction. The medical community is interested in more legislative regulations on patients' responsibility.

Thus, every fourth medical staff member gave a positive answer to the question "Have there been any conflicts with patients in your practice?". The proportion of the reasons was distributed by the respondents as follows: non-compliance with the treatment procedure - 42.9\%; a general increase of aggressiveness towards medical staff members, and thus decrease of respect as a result of reformation process in medicine $-28.6 \%$, the same proportion of respondents marked the specificity of the patient's illness as the cause of conflicts.

As a rule, the formation of a conflict situation between patients and medical staff cannot be settled directly at the moment and place of its uprising. The conflicting party addresses the head management of the organization, and in case the conflict is not settled in their favor, they appeal to higher authorities.

At the same time, only $63.6 \%$ of respondents answered that if conflicts with patients arise, their head management helps to settle this conflict, another $11.5 \%$ of respondents answered that the head management occasionally settles the issue, $5.6 \%$ of respondents answered that such settlement is a rare case, and $4.7 \%$ of medical staff answered, that their leader never settles conflicts with patients (figure 1). 


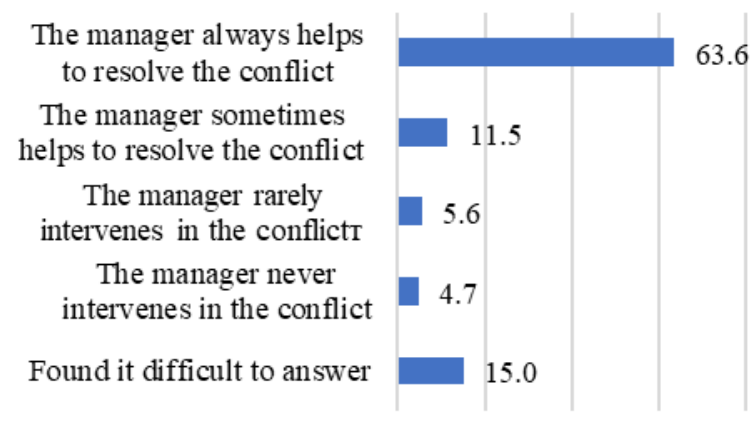

Figure 1 The distribution of answers as for the help from the head management side to settle occurred conflicts with patients, $\%$.

Patients transfer their dissatisfaction with the healthcare system in Russia as a whole to the activities of specific medical staff members. Nowadays the overwhelming majority of doctors point out the increase in the flow of patients' criticism and complaints, which can be regarded as a hidden indicator of public dissatisfaction with the entire system and the quality of life in the country.

After the analysis of patients appeals, it was defined, that $90.5 \%$ of them were complaints, namely $19 \%$ of which concerned paid services, $14 \%$ of which concerned the quality of medical services provided, $19 \%$ of which concerned the institution's work procedures (including the availability of medical care).

Most often it is patients who become the initiators of the conflict. The source of conflicts between persons is a "tight situation". The medical care providing process can be categorized as "tight situations" for a patient with the following characteristics: an individual's awareness of the threat to health, difficulties associated with the regime limitations, obstacles to goals achieving; state of mental tension as a reaction to difficulty; a noticeable change in the usual parameters of activity and communication. This allows the understanding that there are a lot of preconditions for tight situations development in the medical care area, and if they are not prevented, they will result in conflicts.

\section{CONCLUSION}

Thus, the survey of medical staff members conducted by the authors showed that in their daily activities there are factors that can lead to a conflict situation, the main of which is constant changes in activities. There are also grounds for professional burnout of medical staff members, the main of which was a high level of workload in the period before the COVID-19 pandemic. At the present moment, a medical staff workload level significantly increased, and it may cause conflicts in medical care organizations. The most demotivating factor in the medical staff working activity, in their opinion, is the low-level wages, which are specifically typical for the former socialist countries to which Russia belongs.

Nowadays the main source of conflicts in medical care organizations is the relationship with patients, herewith the leaders of the interviewed medical staff members contribute to the settlement of these conflicts in most cases. On transition to a patient-oriented system of relations in healthcare, special attention is required to such conflicts, because of their positive impact on the process of improving the activities of medical organizations.

A number of scientists have marked the positive conflict function as promoting the development. The study of contemporary ideas about the role and content of the conflict, strategies of conflict behavior, training medical staff members in constructive conflict settlements and effective behavior in conflict situations, improving the psychological culture of specialists is relevant for the successful implementation of professional activities in the healthcare system.

\section{REFERENCES}

[1] R.A. Johnson, Management, systems, and society: an introduction, Pacific Palisades, California: Goodyear Pub. Co., 1976, pp. 142-148.

[2] A. Bell, Six ways to resolve workplace conflicts, San Francisco, CA: University of San Francisco, 2002.

[3] B. Hart, Conflict in the workplace. Behavioral Consultants, P.C., 2019. Retrieved from: http://www.excelatlife.com/articles/conflict_at_wor k.htm

[4] P. Knapp, One World - Many Worlds: Contemporary Sociological Theory (2nd Ed.), Harpercollins College Div, 1994, pp. 228-246.

[5] A.V. Shlykov, G.P. Shlykova, Influence of conflict on the efficiency of labor, Economics. Management. Innovations 1 (19) (2019) 48-53.

[6] V.A. Danilov, Conflict management on agricultural enterprises on the example of LLC "Rostov factory of sparkling wines", International Agricultural Journal 2 (2020) 31-35.

[7] A.V. Vasilieva, G.A. Zalomskaya, Upravlenie konfliktami v energosbytovyh kompaniyah Amurskoy oblasti, Management in Russia and Abroad 5 (2018) 90-95.

[8] V.V. Sizova, A.E. Shabanova, Causes of conflicts and methods of teaching staff conflict management, Vestnik of Tver State Technical University. Series: Nauki ob obschestve i humanitarnye nauki 3 (2018) 91-95. 
[9] D. Carr, H.G. Welch, Disclose and Manage Conflicts of Interest at Cancer Centers Reply, Jama Internal Medicine 180(1) (2020) 161-162.

[10] L.K. Gabdulhakova, Upravlenie konfliktami v organizatsii, Human Progress 3(3) (2017) 6.

[11] C. Koch, N. Dreimueller, J. Weisskircher, et al, Teaching Conflicts of Interest and Shared Decision-Making to Improve Risk Communication: a Randomized Controlled Trial, Annual Conference of the German-Association-forMedical-Education (GMA): Munster, Germany, 2017. Journal of General Internal Medicine 35(2) (2020) 473-480.

[12] N.V. Strebkova, Concept of the organizational conflict: definition, history and essence, Vestnik of Saratov Regional Institute of Education Development 1(13) (2018) 66-70.

[13] I. M. Nyazova, Conflict of interests as a conflictogenity component in the organization, Human Progress 6(1) (2020) 6. DOI: https://doi.org/10.34709/IM.161.6 